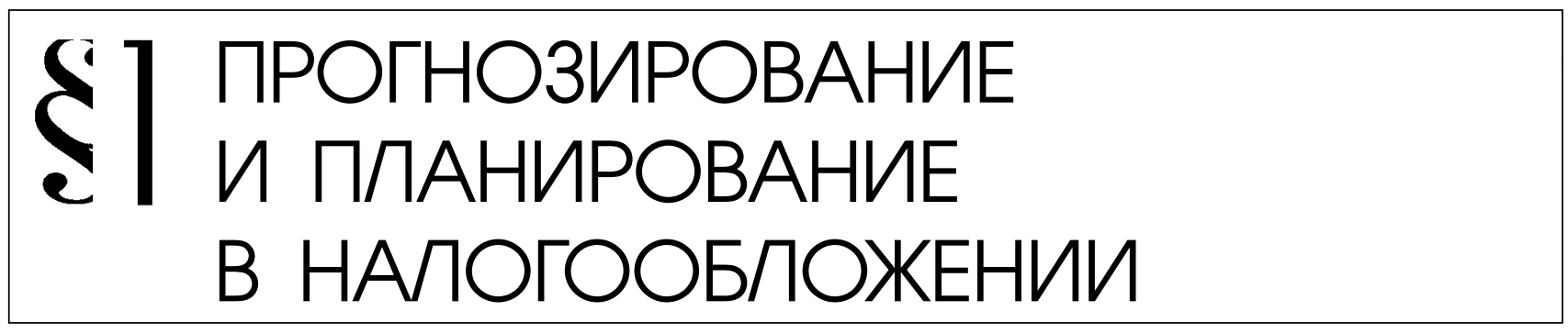

И.В. Оробинская

\title{
МЕХАНИЗМ ОПТИМИЗАЦИИ НАЛОГА НА ПРИБЫЛЬ ОРГАНИЗАЦИЙ ДЛЯ УЧАСТНИКОВ КОНСОЛИДИРОВАННОЙ ГРУППЫ НАЛОГОПЛАТЕЛЬЩИКОВ АПК ПОСРЕДСТВОМ СОЗДАНИЯ РЕЗЕРВНЫХ ФОНДОВ ПО СОМНИТЕЛЬНЫМ ДОЛГАМ
}

Аннотация: Предметом исследования являются экономические отношения, возникающие в процессе налогообложения интегрированных структур АПК РФ. В российском налоговом законодательстве идея консолидированной отчетности нашла свое отражение с вступлением в силу изменений в пункт 1 статьи 246 главы 25 НК РФ. Так, участники консолидированной группы налогоплательщиков исполняют обязанности налогоплательщиков налога на прибыль организаций по консолидированной группе налогоплательщиков в части, необходимой для его исчисления ответственным участником этой группы.В предприятиях холдингового типа, имеет место консолидированные финансовые потоки, то есть все денежные средства условно сливаются воедино и направляются на общие нужды холдинга, а не на погашение затрат какого-либо одного юридического лица. Так, актуальной задачей является перераспределение бухгалтерской прибыли, рассчитанной по итогам каждого квартала на конец годас целью сокращения авансовых налоговых платежей, а значит, и снижения общей финансовой нагрузки и потребности в заемных денежных средствах. Теоретической и методологической основой исследования послужили фундаментальные концепции, представленные в трудах отечественных и зарубежных ученых, законодательные и нормативно-правовые акты государственных органов власти, федеральные законы, Указы Президента и Постановления Правительства РФ, материалы научно-практических конференций, затрагивающие вопросы налогообложения сельскохозяйственных товаропроизводителей.В работе использованы абстрактно-логический, монографический, статистико-экономический, экономико-математический и другие методы экономических исследований. Научная новизна исследования состоит в разработке и апробировании методического подхода к оптимизации налогообложения в интегрированных формированиях АПК посредством создания резервных фондов по сомнительным долгам, позволяющие повысить экономическую эффрективность их функционирования. Создание резерва по сомнительным долгам, по нашему мнению, может позволить сократить налоговую нагрузку в случае неплатежей контрагентов, что приобретает наибольшую актуальность в отношениях между агрохолдингом и контрагентами - сельскохозяйственными предприятиями, которые являются потребителями продукции.

Ключевые слова: Оптимизазия налогообложения, Налог на прибыль, Консолидированная группа, АПК, Резервный фонд, Сельхозтоваропроизводители, Сомнительный долг, Интегрированые формирования, Налоговое планирование, Налоговая нагрузка. 
B российском налоговом законодательстве идея консолидированной отчетности нашла свое отражение с вступлением в силу изменений в пункт 1 статьи 246 главы 25 НК РФ. Так, организации, являющиеся ответственными участниками консолидированной группы налогоплательщиков, признаются налогоплательщиками в отношении налога на прибыль организаций по этой консолидированной группе налогоплательщиков.

Участники консолидированной группы налогоплательщиков исполняют обязанности налогоплательщиков налога на прибыль организаций по консолидированной группе налогоплательщиков в части, необходимой для его исчисления ответственным участником этой группы.

Следует отметить, что право на консолидацию - сложение доходов и убытков, зачет как внутрифирменного оборота передачи доходов и продукции между материнскими и дочерними хозяйственными обществами - в странах развитого правопорядка рассматривается как налоговая льгота инвестиционного характера.

В предприятиях холдингового типа, имеет место консолидированные финансовые потоки, то есть все денежные средства условно сливаются воедино и направляются на общие нужды холдинга, а не на погашение затрат какого-либо одного юридического лица. Так, актуальной задачей является перераспределение бухгалтерской прибыли, рассчитанной по итогам каждого квартала на конец года с целью сокращения авансовых налоговых платежей, а значит, и снижения общей финансовой нагрузки и потребности в заемных денежных средствах.

Налоговое планирование является легальным путем уменьшения налоговых обязательств путем корректировки финансово-хозяйственной деятельности, структуры финансовых и товарных потоков организации при строгом соблюдении налогового законодательства и с учетом сложившейся арбитражной практики.

Следует отметить, что сущность налогового планирования заключается в признании за каждым налогоплательщиком права использовать все допустимые законами средства, приемы и способы для максимального сокращения своих налоговых обязательств.

Так, в основе данного процесса лежит максимально полное и правильное использование всех установленных законом льгот и преимуществ, а также оценка позиции налоговых органов и учет основных направлений налоговой, бюджетной и инвестиционной политики государства.

Основными целями налогового планирования является: оптимизация налоговых платежей, минимизация налоговых потерь по конкретному налогу или по их совокупности, увеличение объема оборотных средств предприятия, повышение эффективности работы организации.

Нам представляется, что описываемый процесс планирования подразумевает оптимизацию налогообложения в целом, разработку ситуационных схем оптимизации налоговых платежей, организацию системы налогообложения для своевременного анализа налоговых последствий различных управленческих решений ${ }^{1}$.

На наш взгляд, оптимизация денежных потоков в предприятиях холдингового типа во многом реализуется за счет сбалансированности финансовых ресурсов и налоговой нагрузки. Мы предлагаем эффективную систему оптимизации денеж-

\footnotetext{
1 Налоги и налогообложение - Москва, № 102013. 730-741 c. DOI: $10.7256 / 1812-8688.2013 .10 .9729$
} 
ного потока по налоговым платежам посредством создания резервных фондов по сомнительным долгам.

Создание резерва по сомнительным долгам, по нашему мнению, может позволить сократить налоговую нагрузку в случае неплатежей контрагентов, что приобретает наибольшую актуальность в отношениях между агрохолдингом и контрагентами - сельскохозяйственными предприятиями, которые являются потребителями продукции. Следует отметить, что порядок создания резерва по сомнительным долгам рассмотрен в ст. 266 НК РФ. По общему правилу сомнительным долгом признается любая задолженность перед налогоплательщиком в случае, если эта задолженность не погашена в сроки, установленные договором, и не обеспечена залогом, поручительством, банковской гарантией. Безнадежными долгами (долгами, нереальными по взысканию) признаются те долги перед налогоплательщиком, по которым истек установленный срок исковой давности, а также те долги, по которым в соответствии с гражданским законодательством обязательство прекращено вследствие невозможности его исполнения, на основании акта государственного органа или ликвидации организации.

Суммы отчислений в эти резервы включаются в состав внереализационных расходов на последний день отчетного (налогового) периода.

Сумма резерва по сомнительным долгам определяется по результатам проведенной на последний день отчетного (налогового) периода инвентаризации дебиторской задолженности и исчисляется следующим образом:

- по сомнительнойзадолженности со сроком возникновения свыше 90 дней в сумму создаваемого резерва вклю- чается полная сумма выявленной на основании инвентаризации задолженности;

- по сомнительной задолженности со сроком возникновения от 45 до 90 дней (включительно) - в сумму резерва включается 50 процентов от суммы, выявленной на основании инвентаризации задолженности;

- по сомнительной задолженности со сроком возникновения до 45 дней не увеличивает сумму создаваемого резерва.

При этом сумма создаваемого резерва по сомнительным долгам не может превышать 10 процентов от выручки отчетного (налогового) периода, определяемой в соответствии со статьей 249 НК РФ. Резерв по сомнительным долгам может быть использован организацией лишь на покрытие убытков от безнадежных долгов, признанных таковыми в порядке, установленном настоящей статьей.

В рамках рассматриваемого круга вопросов по возможной экономии на налоговых платежах, на наш взгляд, следует отметить, что в целях формирования резерва по сомнительным долгам срок отсчитывается не с даты возникновения задолженности, а именно с того момента, когда эта задолженность стала сомнительной.

Также подчеркнем, что при формировании резерва НДС и иные аналогичные обязательные платежи учитываются в составе задолженности, поскольку задолженность, как в бухгалтерском, так и в налоговом учете формируется с учетом этих сумм. Это обстоятельство, в свою очередь, обусловливает собственно размер отчислений на формирование резерва по сомнительным долгам, а эти суммы, как было отмечено выше, в указанном размере включаются в состав внереализационных расходов. 
Оптимизация денежных потоков головной компании при создании резервного фонда по сомнительным долгам

\begin{tabular}{|c|c|c|c|c|c|c|}
\hline Показатели & 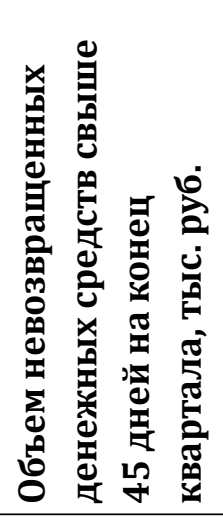 & 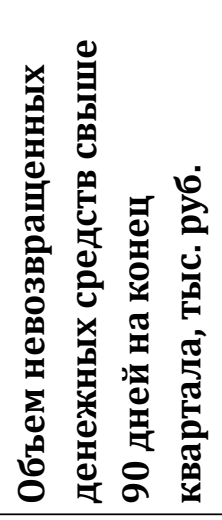 & 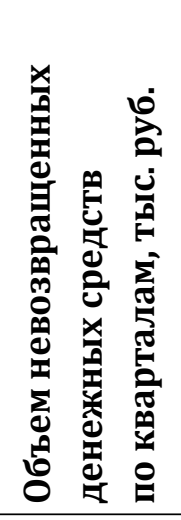 & 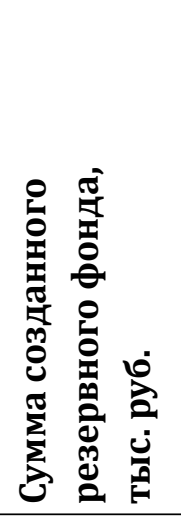 & 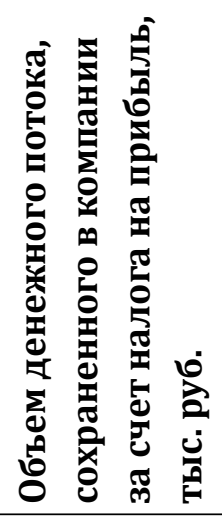 & 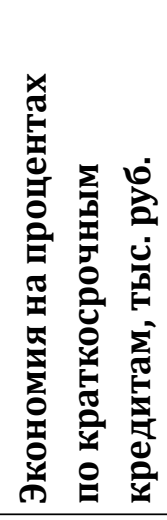 \\
\hline \multicolumn{7}{|l|}{2011 год } \\
\hline 1 квартал & 95120 & 62350 & 109910 & 14580 & 2916 & 583 \\
\hline 2 квартал & 6030 & 53150 & 56165 & 56165 & 11233 & 1693 \\
\hline 3 квартал & 0 & 13000 & 13000 & 13000 & 2600 & 262 \\
\hline 4 квартал & 0 & 10230 & 10230 & 10230 & 2046 & 103 \\
\hline Всего & & & & & 18795 & 2641 \\
\hline \multicolumn{7}{|l|}{2012 год } \\
\hline 1 квартал & 85620 & 52350 & 95160 & 16038 & 3208 & 609 \\
\hline 2 квартал & 5030 & 48151 & 50666 & 50666 & 10133 & 1451 \\
\hline 3 квартал & 0 & 14000 & 14000 & 14000 & 2800 & 268 \\
\hline 4 квартал & 0 & 9530 & 9530 & 9530 & 1906 & 91 \\
\hline Всего & & & & & 18047 & 2419 \\
\hline \multicolumn{7}{|l|}{2013 год } \\
\hline 1 квартал & 75130 & 82320 & 119885 & 17161 & 3432 & 618 \\
\hline 2 квартал & 5030 & 43650 & 46165 & 46165 & 9233 & 1252 \\
\hline 3 квартал & 0 & 12000 & 12000 & 12000 & 2400 & 218 \\
\hline 4 квартал & 0 & 9230 & 9230 & 9230 & 1846 & 84 \\
\hline Всего & & & & & 16911 & 2171 \\
\hline
\end{tabular}

Таким образом, механизм резервирования сомнительных долгов дает неплохие возможности для уменьшения налога на прибыль (табл. 1).

Проведенный в исследуемом интегрированном предприятии анализ дебиторской задолженности показал, что наибольший объем просроченных долгов приходится на первый квартал. Это в основном долги предыдущего года за поставку ХСЗР, семян и техники головной компанией своим контрагентам с пятидесятипроцентной предоплатой и с рассрочкой платежа до конца года. Во втором квартале часть долгов погашается, а часть перераспределяется в категорию просроченных свыше 90 дней. В третьем квартале основная часть долгов погашается в ходе арбитражных решений или мировых соглашений, остаток долгов учитывается в категории просроченных свыше 90 дней. В четвертом квартале погашается 


\section{Экономический эффект от проведения комплекса мероприятий по оптимизации налоговых платежей в интегрированном} формировании АПК, тыс. руб.

\begin{tabular}{|l|c|c|c|}
\hline \multicolumn{1}{|c|}{ Показатели } & $\mathbf{2 0 1 1}$ г. & $\mathbf{2 0 1 2}$ г. & $\mathbf{2 0 1 3}$ г. \\
\hline Выручка от реализации & 1325450 & 1457995 & 1560055 \\
\hline Себестоимость реализованной продукции & 1234220 & 1357642 & 1452677 \\
\hline Прочие расходы & 69858 & 76844 & 82223 \\
\hline Прибыль до налогообложения & 21372 & 23509 & 25155 \\
\hline $\begin{array}{l}\text { Экономия от оптимизации денежных потоков при соз- } \\
\text { дании резервного фонда по сомнительным долгам }\end{array}$ & 2641 & 2419 & 2171 \\
\hline Итого прибыль до налогообложения & 24013 & 25928 & 27326 \\
\hline Налог на прибыль & 4803 & 5186 & 5465 \\
\hline Итого чистая прибыль & 19210 & 20742 & 21861 \\
\hline Экономический эффект & 2641 & 2419 & 2171 \\
\hline
\end{tabular}

большая часть оставшихся просроченных долгов прошлого года, и появляются долги по контрактам текущего года с рассрочкой платежа до 31 октября.

Из описанной выше дебиторской задолженности формируется резерв по сомнительным долгам. Так как выручка первого квартала 2011 г. составляет 145,8 млн руб., то объем резервного фонда может быть не более $10 \%$ от этой суммы, а именно 14,58 млн руб. По оставшимся кварталам объем резервного фонда формируется подобным образом.

Так, создание резерва по сомнительным долгам в исследуемом холдинге позволит увеличить внереализационные расходы и сохранить суммарный объем денежных средств в компании в размере 18,8 млн руб., что позволит снизить потребность головной компании в краткосрочных кредитах на 5,9\%, и иметь чистую экономию на стоимости заемных средств при двадцатипроцентной ставке банковского кредита в размере 2,6 млн руб.

Таким образом, комплекс мероприятий по оптимизации налоговых платежей по- зволяет получить определенный экономический эффект (табл. 2).

Суммарный объем денежных средств, сохраненных в компании при проведении комплекса мероприятий по оптимизации налоговых платежей составит 53,7 млн руб., что дает возможность снизить потребность головной компании в краткосрочных кредитах на 15,2 \%. Экономический эффект от проведенных мероприятий в 2011 г. оценивается в 2,64 млн руб. (2012 г. 2,41 млн руб., 2013 г. - 2,17 млн руб), что позволяет увеличить прибыль головной компании на 12 \% за счет сокращения платы за заемные средства.

Проведенные нами исследования свидетельствуют о том, что применение различных способов налоговой оптимизации позволяет достичь реального экономического эффекта в агрохолдингах.

Основываясь на проведенных теоретических и аналитических исследованиях, мы предлагаем мероприятия, направленные на совершенствование существующей системы налогообложения для сельхозтоваропроизводителей, реализация 
которых будет способствовать повышению доходности и привлечению инвестиций в отрасль.

Очевидно, что низкое налоговое бремя в целом положительно сказывается на функционировании предприятий аграрной сферы и должно способствовать привлечению инвестиции в данный сектор экономики страны. Но вместе с тем в существующей налоговой системе РФ имеют- ся определенные противоречия, которые тормозят этот процесс.

Таким образом, реализация механизма оптимизации налога на прибыль для участников консолидированной группы налогоплательщиков АПК посредством создания резервных фондов по сомнительным долгам будет способствовать формированию, конкурентоспособной и финансово-устойчивой экономики.

\section{Библиография:}

1. Брызгалин А.В. Налоговая оптимизация: принципы, методы, реко-мендации, арбитражная практика / А.В. Брызгалин, В.Р. Берник, А.Н. Голов-кин; под ред. канд. юр. наук А.В. Брызгалина. 4-е изд., перераб. и доп. - М.: Юрайт-Издат, 2007. - 320 с. ;

2. Лукаш Ю.А. Оптимизация налогов. Методы и схемы / Ю.А. Лукаш. - М.: ГроссМедиа, 2006. - 416 c.

3. Налоговый кодекс Российской Федерации: Части первая и вторая. - М.: Юрайт-Издат, 2014. - 642 с.

4. Оптимизация параметров развития производства и налогообложе-ния в интегрированных формированиях АПК: монография / Оробинская И.В., Оробинский А.С., Парахин Ю.Н.; под редакцией профессора Камаляна А.К. - Воронеж: ФГОУ ВПО ВГАУ, 2010. — 199 c.

5. Оробинская И.В. Методические рекомендации по оптимизации на-логообложения горизонтально-интегрированных объединений АПК / И.В. Оробинская //Налоги и налогообложение-Москва, № 10 2013. - 730-741 с.

6. Калаков Р.Н. Налогообложение инноваций: современное состояние и перспективы // NB: Финансовое право и управление. - 2012. - 1. - C. 21 - 82. URL: http://www.enotabene.ru/flc/article_388.html

7. Ермакова М.С. Особенности формирования учетной политики для целей налогообложения агрохолдинга // NB: Финансовое право и управление. - 2013. - 2. - С. 77 105. DOI: 10.7256/2306-4234.2013.2.778. URL: http://www.e-notabene.ru/flc/article_778. html

8. Оробинская И.В. Методические рекомендации по оптимизации налогообложения горизонтально - интегрированныхобъединений АПК // Налоги и налогообложение. 2013. - 10. - C. 730 - 741. DOI: 10.7256/1812-8688.2013.10.9729.

9. Никитина А.Х. Налоговые льготы для российских сельхозтоваропроизводителей // Налоги и налогообложение. - 2013. - 8. - С. 566 - 571. DOI: 10.7256/18128688.2013.8.9406.

10. И.В. Оробинская Эволюция становления и развития системы налогообложения сельскохозяйственных предприятий в России и зарубежных странах // Налоги и налогообложение. - 2012. - 8. - С. $54-63$. 
11. Оробинская И.В. Основы оптимизации налогообложения сельскохозяйственных товаропроизводителей в России // Налоги и налогообложение. - 2013. - 11. - С. 807 817. DOI: $10.7256 / 1812-8688.2013 .11 .9584$.

12. И.В. Оробинская Особенности и анализ применения различных режимов налогообложения для сельскохозяйственных товаропроизводителей в России // Налоги и налогообложение. - 2013. - 2. - C. 85 - 95. DOI: 10.7256/18128688.2013.02.1.

13. Аринин Е.А. Теоретические аспекты организационно-правового механизма налогообложения в Российской Федерации. // NB: Финансовое право и управление. - 2013. 4. - C. 1 - 29. DOI: 10.7256/2306-4234.2013.4.855. URL: http://www.e-notabene.ru/flc/ article_855.html

14. Антонова Е.В. Выбор методики определения налоговой нагрузки на предприятии // Налоги и налогообложение. - 2013. - 5. - C. 350 - 363. DOI: 10.7256/18128688.2013.5.8770.

\section{References:}

1. Bryzgalin A.V. Nalogovaya optimizatsiya: printsipy, metody, reko-mendatsii, arbitrazhnaya praktika / A.V. Bryzgalin, V.R. Bernik, A.N. Golov-kin; pod red. kand. yur. nauk A.V. Bryzgalina. 4-e izd., pererab. i dop. - M.: Yurait-Izdat, 2007. - 320 s. ;

2. Lukash Yu.A. Optimizatsiya nalogov. Metody i skhemy / Yu.A. Lukash. - M.: GrossMedia, 2006. - $416 \mathrm{c}$.

3. Nalogovyi kodeks Rossiiskoi Federatsii: Chasti pervaya i vtoraya. - M.: Yurait-Izdat, 2014. $642 \mathrm{~s}$.

4. Optimizatsiya parametrov razvitiya proizvodstva i nalogooblozhe-niya v integrirovannykh formirovaniyakh APK: monografiya / Orobinskaya I.V., Orobinskii A.S., Parakhin Yu.N.; pod redaktsiei professora Kamalyana A.K. - Voronezh: FGOU VPO VGAU, 2010. - 199 c.

5. Orobinskaya I.V. Metodicheskie rekomendatsii po optimizatsii na-logooblozheniya gorizontal'no-integrirovannykh ob"edinenii APK / I.V. Orobinskaya //Nalogi i nalogooblozhenie-Moskva, № 10 2013. - 730-741 s.

6. Kalakov R.N. Nalogooblozhenie innovatsii: sovremennoe sostoyanie i perspektivy // NB: Finansovoe pravo i upravlenie. - 2012. - 1. - C. 21 - 82. URL: http://www.e-notabene.ru/ flc/article_388.html

7. Ermakova M.S. Osobennosti formirovaniya uchetnoi politiki dlya tselei nalogooblozheniya agrokholdinga // NB: Finansovoe pravo i upravlenie. - 2013. - 2. C. 77 - 105. DOI: 10.7256/2306-4234.2013.2.778. URL: http://www.e-notabene.ru/ flc/article_778.html

8. Orobinskaya I.V. Metodicheskie rekomendatsii po optimizatsii nalogooblozheniya gorizontal'no - integrirovannykh ob"edinenii APK // Nalogi i nalogooblozhenie. - 2013. 10. — C. 730 - 741. DOI: 10.7256/1812-8688.2013.10.9729.

9. Nikitina A.Kh. Nalogovye l'goty dlya rossiiskikh sel'khoztovaroproizvoditelei // Nalogi i nalogooblozhenie. - 2013. - 8. - C. 566 - 571. DOI: 10.7256/18128688.2013.8.9406. 
10. I.V. Orobinskaya Evolyutsiya stanovleniya i razvitiya sistemy nalogooblozheniya sel'skokhozyaistvennykh predpriyatii v Rossii i zarubezhnykh stranakh // Nalogi i nalogooblozhenie. -2012 . - 8. - C. $54-63$.

11. Orobinskaya I.V. Osnovy optimizatsii nalogooblozheniya sel'skokhozyaistvennykh tovaroproizvoditelei v Rossii // Nalogi i nalogooblozhenie. - 2013. - 11. - C. 807 - 817. DOI: 10.7256/1812-8688.2013.11.9584.

12. I.V. Orobinskaya Osobennosti i analiz primeneniya razlichnykh rezhimov nalogooblozheniya dlya sel'skokhozyaistvennykh tovaroproizvoditelei v Rossii // Nalogi i nalogooblozhenie. 2013. - 2. - C. 85 - 95. DOI: 10.7256/1812-8688.2013.02.1.

13. Arinin E.A. Teoreticheskie aspekty organizatsionno-pravovogo mekhanizma nalogooblozheniya v Rossiiskoi Federatsii. // NB: Finansovoe pravo i upravlenie. - 2013. 4. - C. 1 - 29. DOI: 10.7256/2306-4234.2013.4.855. URL: http://www.e-notabene.ru/flc/ article_855.html

14. Antonova E.V. Vybor metodiki opredeleniya nalogovoi nagruzki na predpriyatii // Nalogi i nalogooblozhenie. - 2013. - 5. - C. 350 - 363. DOI: 10.7256/1812-8688.2013.5.8770. 